\title{
Experimental Investigating Effect of Reprocessing on Properties of Composites based on Recycled Polypropylene
}

\author{
F. Gu, P. Hall, N.J. Miles \\ Faculty of Science and Engineering \\ Nottingham University \\ No. 199, East Taikang Rd, Ningbo, Zhejiang, China. P. R.
}

\begin{abstract}
This paper is aimed to provide knowledge and understanding to promote the use of recycled materials via experimental study. In this paper, for the first time, effect of reprocessing on properties of recycled $\mathrm{PP} /$ talc composites has been investigated via series of experimental tests, while both virgin and recycled $P P$ were used as comparatives. The materials were reprocessed in two different routes, multiple extrusion cycles and multiple injection moulding cycles. Some materials were taken out for testing during each cycle. The tests include mechanical, rheological and thermal. The results were plotted and discussed, and for the first time, results from the two different reprocessing routes were compared. Some phenomena were observed and fitted in others' studies and prediction. Also, the complexity of composites made from recycled materials under reprocessing was detected, and in need of further research.
\end{abstract}

Keywords-reprocessing; recycled; polypropylene; talc-filled; extrusion; injection moulding; chain-scission

\section{INTRODUCTION}

Due to various reasons, such as pressure from legislations [1 3], saving natural resource (mainly crude oil which plastics are made from), reducing cost, landfill and emission, plastic recycling has attracted a broad interest since 1950s. Even after decades of practices and researches, it still poses a difficult challenge both for industry and for academia. Comparing with landfill, incineration for energy recovery and chemical recycling, mechanical recycling has been proved to be the most viable way to deal with the challenge, for it reduces the consumption of natural resources as well as a reduced landfill and material cost [4]. It was estimated that using recycled plastics could reduce greenhouse gas emissions by about $80 \%$ [5]. But when compared to virgin plastic, recycled plastic tend to show lesser performances due to degradation phenomena that occur during the product's first life and reprocessing [6 12]. Thus, the effect of reprocessing became a popular topic, and many studies have investigated the effect of reprocessing on their structure, thermal and mechanical properties [4, 13 17]. González-González, et al. [14] have identified the chain scissions during multiple extrusion which are linked to the melt temperature and resulted molecular weight losses. Brennan, et al. [18] recovered acrylonitrile-butadiene-styrene (ABS) and high-impact polystyrene (HIPS) from waste computer equipments, and found elongation at break and impact strengths were reduced considerably during reprocessing. Su, et al. [15] investigated the influence of reprocessing on the mechanical properties and structure of polyamide 6 , and reported an increment in the tensile yield stress, flexural strength and modulus but a decrement in Izod impact strength and the molecular weight. Scaffaro, et al. [4] found the tensile, flexural and impact properties of $\mathrm{ABS}$ deteriorated with reprocessing.

Polypropylene (PP), as one of the most common plastic materials, is usually being used in various applications while mixing with all sorts of fillers, such as minerals [19 23], clays [24] and fibres [25]. Among these fillers, talc is one of the most commonly used mineral filler which improves both the thermal and mechanical properties of PP [23], and a few studies have been conducted on reprocessing of talc-filled PP. Guerrica-Echevarría, et al. [13] studied talc-filled PP undergone multiple injection moulding cycles, and found that molecular weight decreased and break properties (such as Elongation at break) are related to the filler content and processing conditions. Bahlouli, et al. [26] studied the recycling effects on two high impact polypropylenes (HiPP), and found a better thermal and structural stability for talc filled HiPP. Wang, et al. [23] pointed out that during the repeated extrusion cycles, talc in PP slightly increased the Young's modulus and the yield strength.

Yet, most current studies only focused on reprocessing effect on virgin composites, such as talc-filled virgin PP, or recycling of waste plastics from different sources. To the best of our knowledge, the influence of the filler content and reprocessing cycle numbers on the properties of recycled PP-based composites has received little to no attention. Lack of research on recycled plastic based materials would certainly limit their use, and it is both uneconomic and environmental-unfriendly. Further, there is no research which focused on comparison of the effects of two major reprocessing routes (extrusion and injection moulding) on composites has been reported, and in industrial context, mechanical recycling usually involves both of the two procedures [27, 28]. In this paper, with the aim of promoting the understanding and use of composites based on recycled plastics, the effects from both extrusion and injection moulding cycles on the properties of talc-filled recycled PP composites were investigated via experimental methods. The results were discussed and correlated with previous researches, 
which would provide a comprehensible knowledge base for reusing recycled plastics and their composites.

\section{EXPERIMENTAL}

\section{A. Materials}

The virgin PP (VPP) material used was a block co-polymer mainly being used for manufacturing automobile parts, with a trade-name of PPB-MO2-V and produced by Yangzi Sinopec. The material was used as received, and has an average particle size of $3.0 \mathrm{~mm}$, density of $0.9 \mathrm{~g} \mathrm{~cm}^{-3}$, as shown in Figure 1 . The recycled PP (RPP) used was some grey pellet recovered from white post-customer storage boxes, has an average particle size of $3.0 \mathrm{~mm}$, density of $1.0 \mathrm{~g} \mathrm{~cm}^{-3}$, as shown in Figure 2, and was used as received.

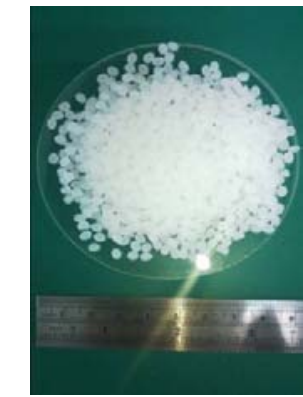

FIGURE I. PPB-MO2-V (VPP).

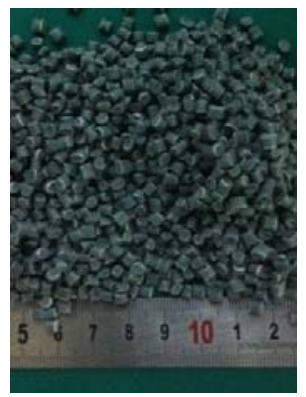

FIGURE II. GREY RECYCLED PP (RPP).

The talcum powder (talc) used in this work was bought from a local factory, has an average particle size of $12.5 \mathrm{um}$, a density of $2.7 \mathrm{~g} \mathrm{~cm}^{-3}$, as shown in Figure 3, and was used as received.

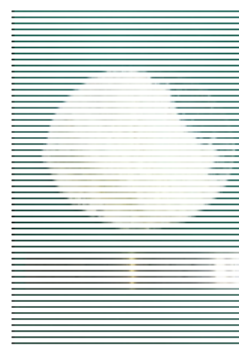

FIGURE III. TALCUM POWDER.

The coupling agent, maleic anhydride grafted polypropylene (MAPP) used in this work was bought from Nanjing Deba Chemical Co.,Ltd, has an average particle size of $2.5 \mathrm{~mm}$, a density of $0.9 \mathrm{~g} \mathrm{~cm}^{-3}$, with the grafted rate of $0.8 \%$, as shown in Figure 4, and was used as received.

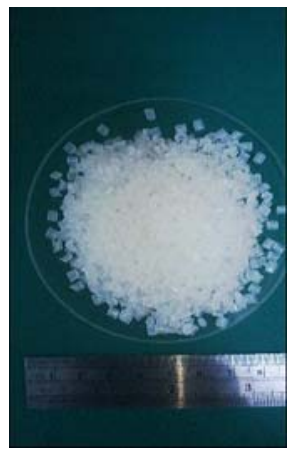

FIGURE IV. MAPP 1.

The compositions used in the paper were shown in Table

TABLE I. THE COMPOSITIONS OF TESTING MATERIALS (WT.\%).

\begin{tabular}{|l|l|l|l|l|}
\hline $\begin{array}{l}\text { Designati } \\
\text { on }\end{array}$ & PPB-MO-V & Grey RPP & Talc & MAPP \\
\hline VPP & 100 & 0 & 0 & 0 \\
\hline RPP & 0 & 100 & 0 & 0 \\
\hline RPP-T20 & 0 & 75 & 20 & 5 \\
\hline RPP-T40 & 0 & 50 & 40 & 10 \\
\hline
\end{tabular}

B. Sampling and Reprocessing

\section{1) Extrusion cycles}

All materials for multiple extrusion cycles were processed by a Kangrun KRSHJ-20 extruder; a co-rotating, intermeshing twin-screw extruder, with screw diameter of $22 \mathrm{~mm}$ and $\mathrm{L} / \mathrm{D}=44$. A single-screw feeder attached to the hopper was used for all the PP pellets. The processing temperatures were allowed to increase from $180^{\circ} \mathrm{C}$ to $200^{\circ} \mathrm{C}$ going from the hopper to the third barrel, and the temperatures of the last three barrels remained at $200^{\circ} \mathrm{C}$, while the die temperature was set at $200^{\circ} \mathrm{C}$. The screw rotation speed was $180 \mathrm{rpm}$, and the total mass flow rate was $5 \mathrm{~kg} \mathrm{~h}^{-1}$. Blended strands were extruded into a water bath for cooling, and then pelletized by a cutter. The average extruded pellet size was $2.8 \mathrm{~mm}$. This process was repeated 5 times under the same operating conditions, so the grinded material of each cycle was the starting material for the following reprocessing cycles.

Some pellets were taken in every extrusion cycle for making testing sample pieces. Those taken pellets were dried in a dry oven at $85^{\circ} \mathrm{C}$ for $12 \mathrm{~h}$ with constant air flow to keep the moisture content below $1 \%$ before being fed into the injection moulding machine.

Then these were injection moulded into ISO standard test specimens using a Haitian MA1200/370 injection moulding machine, and 2 (tensile pieces) or 4 (flexural or impact pieces) test specimens were produced per single injection moulding process, see Figure 5. The temperatures of five heating barrels were set at $190^{\circ} \mathrm{C}, 192^{\circ} \mathrm{C}, 195^{\circ} \mathrm{C}, 200^{\circ} \mathrm{C}, 200^{\circ} \mathrm{C}$, with injection pressure of $50 \mathrm{MPa}$, injection speed of $50 \mathrm{~g}$ per second, packing pressure of $30 \mathrm{MPa}$ for $10 \mathrm{~s}$, cooling in moulds was allowed for $10 \mathrm{~s}$. The mould was pre-heated to $50^{\circ} \mathrm{C}$. The 
processing parameters were set in accordance with real manufacture [27].

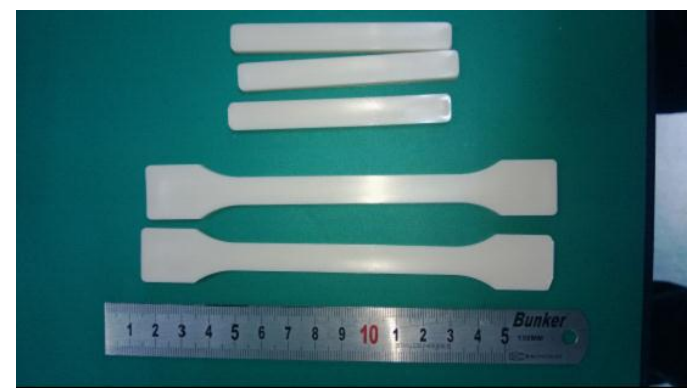

FIGURE V. TESTING SAMPLE PIECES.

\section{2) Injection moulding cycles}

All materials for multiple injection moulding cycles were processed by a Kangrun KRSHJ-20 extruder; a co-rotating, intermeshing twin-screw extruder, with screw diameter of 22 $\mathrm{mm}$ and $\mathrm{L} / \mathrm{D}=44$. A single-screw feeder attached to the hopper was used for all the PP pellets. The processing temperatures were allowed to increase from $180^{\circ} \mathrm{C}$ to $200^{\circ} \mathrm{C}$ going from the hopper to the third barrel, and the temperatures of the last three barrels remained at $200^{\circ} \mathrm{C}$, while the die temperature was set at $200^{\circ} \mathrm{C}$. The screw rotation speed was $180 \mathrm{rpm}$, and the total mass flow rate was $5 \mathrm{~kg} \mathrm{~h}^{-1}$. Blended strands were extruded into a water bath for cooling, and then pelletized by a cutter. The average extruded pellet size was $2.8 \mathrm{~mm}$.

The extruded pellets were dried in a dry oven at $85^{\circ} \mathrm{C}$ for $12 \mathrm{~h}$ with constant air flow to keep the moisture content below $1 \%$ before being fed into the injection moulding machine.

Then these were injection moulded into ISO standard test specimens using a Haitian MA1200/370 injection moulding machine, and 2 (tensile pieces) or 4 (flexural or impact pieces) test specimens were produced per single injection moulding process, the same as that shown in Figure 5. The temperatures of five heating barrels were set at $190^{\circ} \mathrm{C}, 192^{\circ} \mathrm{C}, 195^{\circ} \mathrm{C}, 200^{\circ} \mathrm{C}$, $200^{\circ} \mathrm{C}$, with injection pressure of $50 \mathrm{MPa}$, injection speed of $50 \mathrm{~g}$ per second, packing pressure of $30 \mathrm{MPa}$ for $10 \mathrm{~s}$, Cooling in moulds was allowed for $10 \mathrm{~s}$. The mould was pre-heated to $50^{\circ} \mathrm{C}$. The processing parameters were set in accordance with real manufacture [27].

This process was repeated 5 times under the same operating conditions. In each injection cycle, parts of the specimens were used for characterization purposes, while the remainders were grinded by a cutting mill (Retsch, Germany, model SM 200, as shown in Figure 6 left) in order to be reprocessed. The $4 \mathrm{~mm}$ sieve used was shown in Figure 6 right The shredded plastic pellets were shown in Figure 7, with an average particle size of $3 \mathrm{~mm}$.
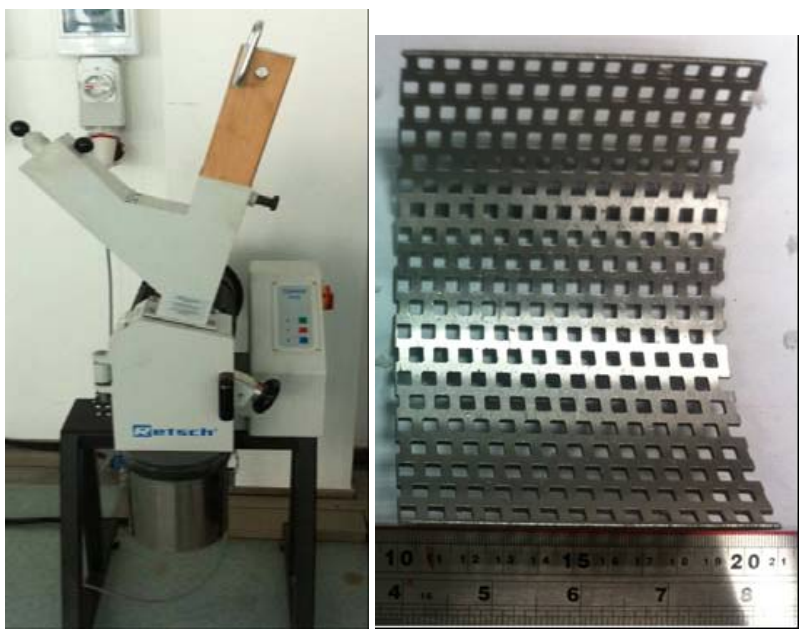

FIGURE VI. LEFT: CUTTING MILL, MODEL SM 200; RIGHT: THE 4 mm SIEVE.

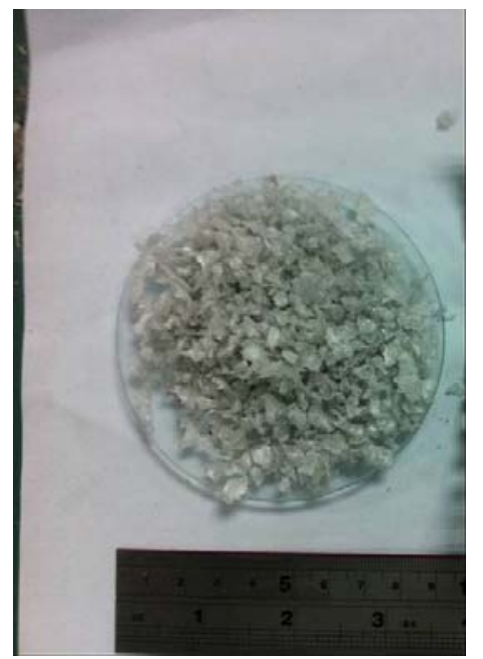

FIGURE VII. SHREDDED PLASTIC PELLETS

\section{Sampling and Reprocessing}

\section{1) Mechanical}

The mechanical properties of composites were evaluated in terms of tensile, flexural, and impact properties, and all sample specimens were conditioned at $23^{\circ} \mathrm{C}$ and $50 \%$ R.H. for over $88 \mathrm{~h}$ before testing in accrodance with ISO291 specifications [30].

The tensile properties tested were tensile strength, yield strength and elongation at break, assessed in accordance with ISO527 specifications [31]. The gauge distance is $110 \mathrm{~mm}$ with fixers' moving speed of $50 \mathrm{~mm} \mathrm{~min}{ }^{-1}$, sampling rate at $200 \mathrm{pts} \mathrm{s}^{-1}$, full-scale load range of $20 \mathrm{kN}$, performed on a Gotech Universal Testing Machine (model TCS-2000NE) at room temperature of $23^{\circ} \mathrm{C}$ and at $50 \%$ R.H. The tensile modulus was obtained by an extensometer (Epsilon Technology Co.Ltd) at tensile elongation of $1 \%$.

The flexural properties tested were flexural modulus and flexural strength, assessed in accordance with ISO178 specifications [32]. The span was set to $64 \mathrm{~mm}$ at a crosshead 
speed of $2 \mathrm{~mm} \mathrm{~min}^{-1}$, sampling rate at $200 \mathrm{pts} \mathrm{s}^{-1}$, full-scale load range of $20 \mathrm{kN}$, performed on a Gotech Universal Testing Machine (model TCS-2000NE) at a room temperature of $23^{\circ} \mathrm{C}$ and at $50 \%$ R.H.

8 sample pieces were tested for each property tested and the average result taken if the coefficient of variance met the required limits (5\% in accordance with ISO2602 specifications [33]).

\section{2) Rheological}

The flow behaviour of the materials was assessed using steady and dynamic shear rheology. The test was performed by utilising a dual-bore capillary rheometer (Rosand RH2200, Malvern Instruments) with two capillary dies with same radius of $1 \mathrm{~mm}$ but different length/radius ratios. Samples were pre-heated in the dual barrels at $190^{\circ} \mathrm{C}$ for $2 \mathrm{~min}$, and measurements were carried out at $190^{\circ} \mathrm{C}$ under a shear rate ranging from 10 to $5000 \mathrm{~s}^{-1}$, at room temperature of $23^{\circ} \mathrm{C}$ and at $50 \%$ R.H. Viscosity is plotted against shear rate, and the power law model was used to describe relationship between viscosity and shear rate as described in Eq.(1):

$$
\eta=K \gamma^{n-1}
$$

where the consistency $K$ corresponds to the viscosity value for a shear rate $\gamma$ of $1 \mathrm{~s}^{-1}$ and the power-law index $n$ characterizes the deviation of the Newtonian behaviour.

\section{3) Thermal}

The thermal properties of the materials were measured in form of the temperatures of deflection under load (TDL). The tests were conducted by using an HDT-VICAT test processor (CEAST model 6911.000) according to ISO75 [29], with constant heating rate of $50{ }^{\circ} \mathrm{C} \mathrm{h}-1$ and a load of $0.45 \mathrm{MPa}$. The samples were immersed in silicon oil which filled the tank and preheated for $4 \mathrm{~min}$ at $40^{\circ} \mathrm{C}$, therefore the tests were carried out at a room temperature of $23^{\circ} \mathrm{C}$ and at $50 \%$ R.H. An average 6 samples were prepared and tested in each group.

\section{RESUlTS AND DISCUSSION}

In this session, the following equation was used to calculate the degradation rate $(D R)$ of the composites' performance which was applied for all properties:

$$
D R=\frac{P_{O}-P_{A}}{P_{O}} \times 100 \%
$$

in which, the symbol $P_{O}$ denotes the original performance obtained from initial tests once the specimens were made, the symbol $P_{A}$ denotes he performance obtained after the ageing procedures were performed.

\section{A. Effect of Reprocessing}

Some of the experimental results from repeated extrusion cycles set were plotted in figures below.

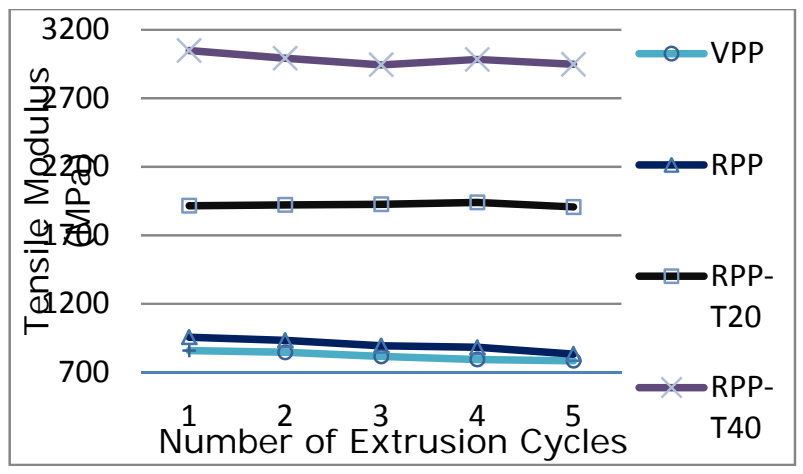

FIGURE VIII. PLOT OF TENSILE MODULUS (MPA) AGAINST NUMBER OF EXTRUSION CYCLES.

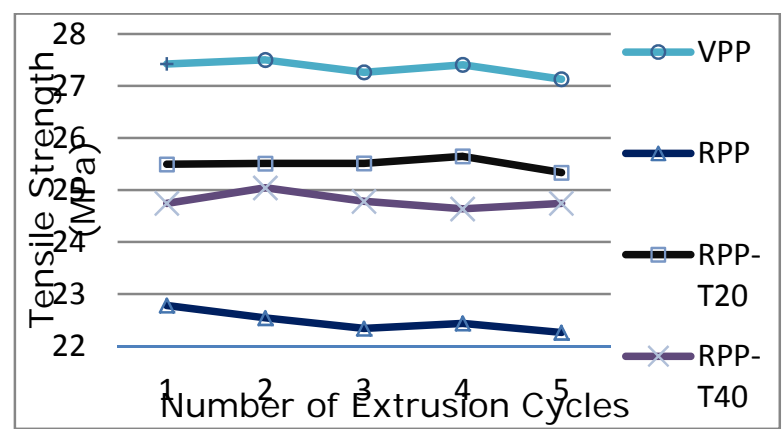

FIGURE IX. PLOT OF TENSILE STRENGTH (MPA) AGAINST NUMBER OF EXTRUSION CYCLES.

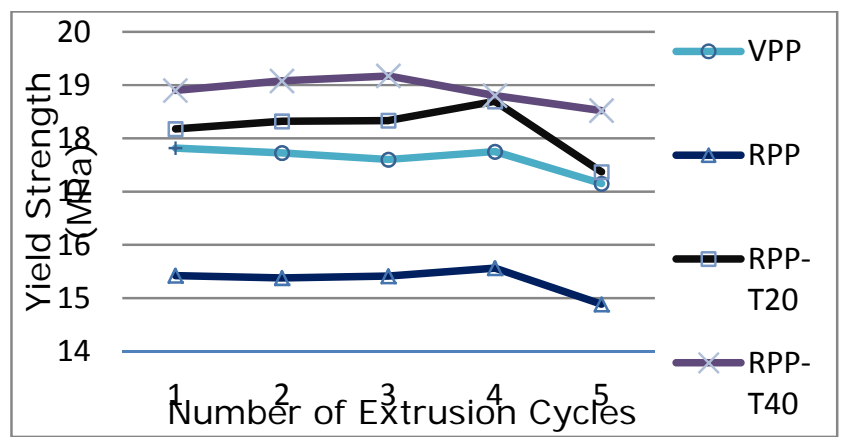

FIGURE X. PLOT OF YIELD STRENGTH (MPA) AGAINST NUMBER OF EXTRUSION CYCLES.

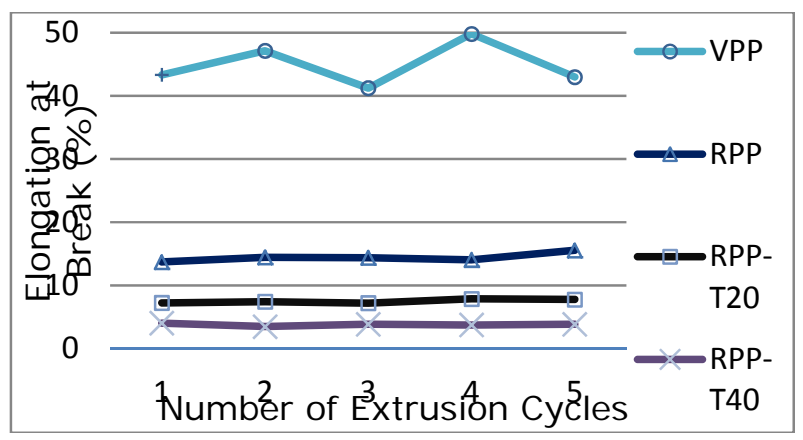

FIGURE XI. PLOT OF ELONGATION AT BREAK (\%) AGAINST NUMBER OF EXTRUSION CYCLES. 


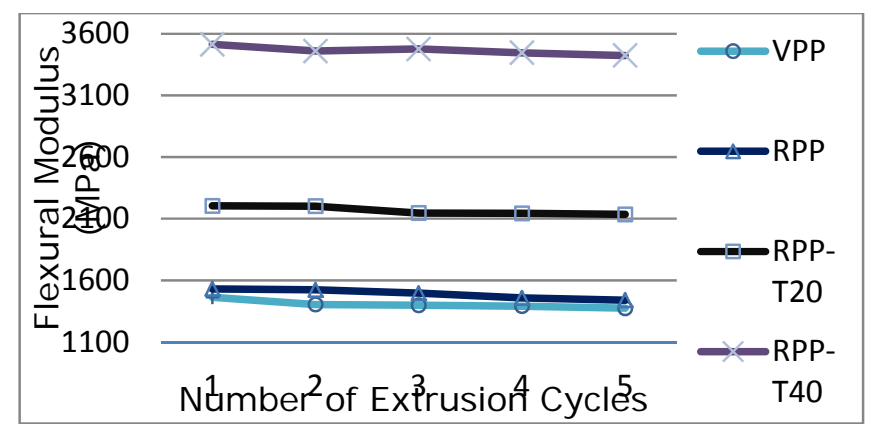

FIGURE XII. PLOT OF FLEXURAL MODULUS (MPA) AGAINST NUMBER OF EXTRUSION CYCLES.

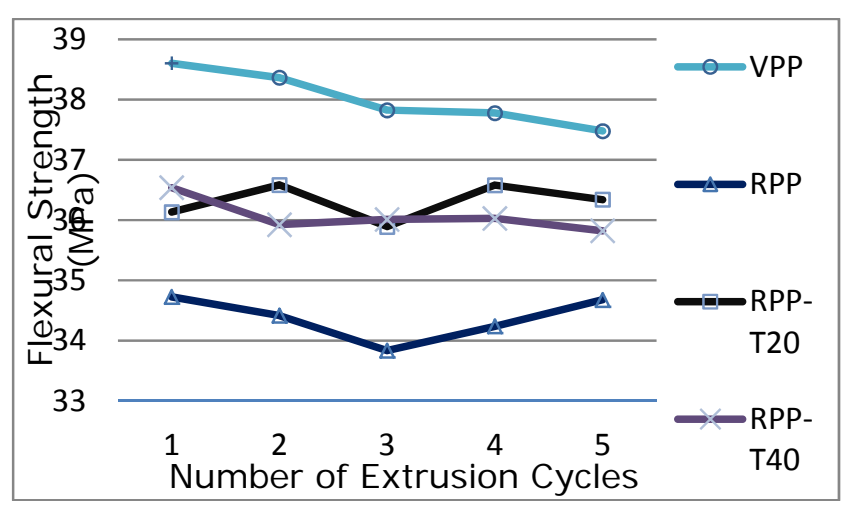

FIGURE XIII. PLOT OF FLEXURAL STRENGTH (MPA) AGAINST NUMBER OF EXTRUSION CYCLES.

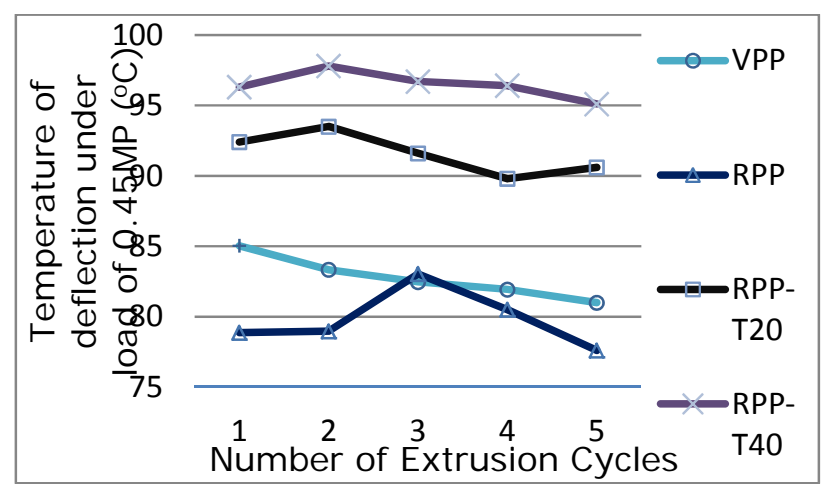

FIGURE XIV. PLOT OF TDL $\left({ }^{\circ} \mathrm{C}\right)$ AGAINST NUMBER OF EXTRUSION CYCLES.

From the figures shown above, the performance of the virgin PP decreased slowly with the number of extrusion cycles, except for elongation at break. This probably resulted from chain-scissions in polymers occurred in elevated temperatures and rotating shear forces $[8,9,14]$.

For recycled PP and talc-filled recycled composites, some properties exhibited a little improvement with reprocessing cycles initially and decreased with further extrusion, such as yield strength and TDL, while other properties are shown to be deteriorated shown to be slightly with reprocessing cycles. The elongation at break and flexural strength of recycled PP remained stable, and were slightly increased at the 5th cycle. For talc-filled recycled PP composites, their performances were comparatively more stable during repeated extrusions except for elongation at break. The talc content improved the mechanical and thermal properties of recycled PP as predicted $[20,23]$.

$D R$ s of some properties during extrusion cycles were summarized in Table.2 using Eq.(2).

TABLE II. DRS OF SOME PROPERTIES DURING EXTRUSION CYCLES (\%, COMPARING WITH THE 1ST PROCESS).

\begin{tabular}{|c|c|c|c|c|c|}
\hline & $\begin{array}{l}\text { Number } \\
\text { of Cycles }\end{array}$ & VPP & RPP & RPP-T20 & RPP-T40 \\
\hline \multirow{4}{*}{$\begin{array}{l}\text { Tensile } \\
\text { Modul } \\
\text { us }\end{array}$} & 2 nd & 1.42 & 2.49 & -0.33 & 1.85 \\
\hline & 3 rd & 4.89 & 6.50 & -0.54 & 3.43 \\
\hline & 4th & 7.54 & 7.79 & -1.23 & 2.14 \\
\hline & 5 th & 8.53 & 12.86 & 0.48 & 3.31 \\
\hline \multirow{4}{*}{$\begin{array}{l}\text { Tensile } \\
\text { Strengt } \\
\mathrm{h}\end{array}$} & 2nd & -0.28 & 1.06 & -0.06 & -1.21 \\
\hline & $3 \mathrm{rd}$ & 0.58 & 1.94 & -0.07 & -0.15 \\
\hline & 4th & 0.06 & 1.51 & -0.60 & 0.43 \\
\hline & 5 th & 1.07 & 2.29 & 0.63 & 0.00 \\
\hline \multirow{4}{*}{$\begin{array}{l}\text { Yield } \\
\text { Strengt } \\
\mathrm{h}\end{array}$} & 2nd & 0.50 & 0.30 & -0.79 & -0.95 \\
\hline & $3 \mathrm{rd}$ & 1.19 & 0.07 & -0.87 & -1.44 \\
\hline & 4th & 0.36 & -0.91 & -2.84 & 0.51 \\
\hline & 5 th & 3.73 & 3.49 & 4.44 & 2.00 \\
\hline \multirow{4}{*}{$\begin{array}{l}\text { Flexura } \\
1 \\
\text { Modul } \\
\text { us }\end{array}$} & 2nd & 3.95 & 0.50 & 0.12 & 1.54 \\
\hline & $3 \mathrm{rd}$ & 4.37 & 2.35 & 2.65 & 1.07 \\
\hline & 4 th & 4.87 & 4.79 & 2.76 & 1.94 \\
\hline & 5 th & 6.04 & 6.03 & 3.13 & 2.55 \\
\hline \multirow{4}{*}{$\begin{array}{l}\text { Flexura } \\
1 \\
\text { Strengt } \\
\mathrm{h}\end{array}$} & 2nd & 0.62 & 0.89 & -1.24 & 1.68 \\
\hline & $3 \mathrm{rd}$ & 2.01 & 2.57 & 0.67 & 1.44 \\
\hline & 4th & 2.14 & 1.40 & -1.23 & 1.39 \\
\hline & 5 th & 2.92 & 0.14 & -0.57 & 1.96 \\
\hline \multirow[t]{4}{*}{ TDL } & 2nd & 2.00 & -0.13 & -1.19 & -1.56 \\
\hline & $3 \mathrm{rd}$ & 3.02 & -5.28 & 0.87 & -0.42 \\
\hline & 4 th & 3.65 & -2.07 & 2.81 & -0.10 \\
\hline & 5 th & 4.74 & 1.61 & 1.95 & 1.25 \\
\hline \multicolumn{2}{|l|}{ Average } & 2.91 & 2.17 & 0.37 & 0.94 \\
\hline
\end{tabular}

In Table 2, virgin PP showed the largest $D R$ values, because at low molecular weight (MW), the chain scission is random, but at higher MW it becomes MW-dependent, increasing with MW [35], and MW of virgin PP is larger than recycled PP [36].

In repeated heat-and-shear-involving cycles, the polymeric chain lengths become more unified than original lengths and MW, as shown in other's study [35], and the amorphous phase between the lamellae that has an increased mobility is increasing with the number of reprocesses [22], it could gave those polymers a better elongation at break. On the other hand, the presence of talc and contamination within PP matrix resulted in an increase in crystallinity [19, 23, 37], which would increase tensile properties, and reduce elongation at break. Thus, it is highly complicated in fully understand the pattern of recycled PP/talc composites, as shown in figures and Table.2, and needs further study. Still, the stabilizing effect of talc content was observed in recycled composites, as it did same effect on reprocessing of virgin PP/talc composites $[23,26,37]$.

For rheological behaviours in the form of shear viscosity plot of the composites shown in Figure 15, and it quite obvious that reprocesses decreased the shear viscosity of virgin material, which might contribute to chain-scission actions took place in elevated temperatures during reprocessing. However, some talc-filled recycled composite 
(RPP-T20) was comparatively more stable during multiple heat-involving procedures, as shown in Figure 15.

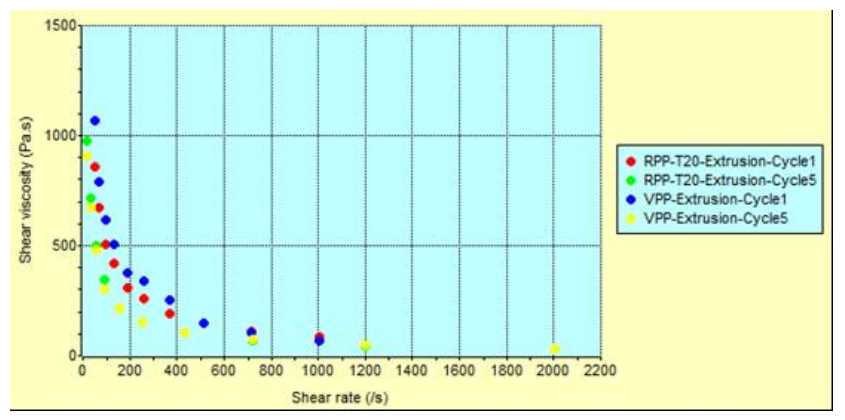

FIGURE XV. SHEAR VISCOSITY PLOT OF MULTIPLE EXTRUSIONS.

The results from repeated injection moulding cycles have shown the same pattern. It is supposed that the presence of talc does not cast a significant influence on the degradation mechanisms of the material matrix [13]), and the stability of recycled $\mathrm{PP} /$ talc composites compared might due to a gradual increase of delamination and dispersion of talc particles or agglomerates during the successive reprocessing, which resulted in an increased number of particles and a decreased particle size [23]. The consistency of flow properties of recycled $\mathrm{PP} /$ talc composites could lead to a more stable production rate, which would facilitate the use of such composites.

\section{B. Comparison of Effect on Recycled Composites}

Tensile results of talc-filled recycled composites from repeated injection moulding cycles set were plotted in Figure 16 to Figure 18, with comparison with multiple extrusion test set, since the tensile properties were found to be critical properties in reprocessing study [34].

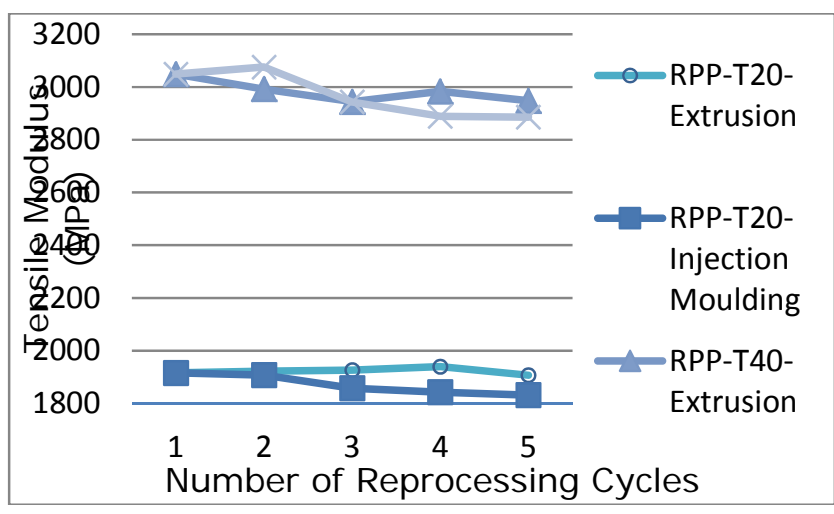

FIGURE XVI. PLOT OF TENSILE MODULUS (MPA) AGAINST NUMBER OF INJECTION MOULDING CYCLES COMPARING WITH EXTRUSION CYCLES

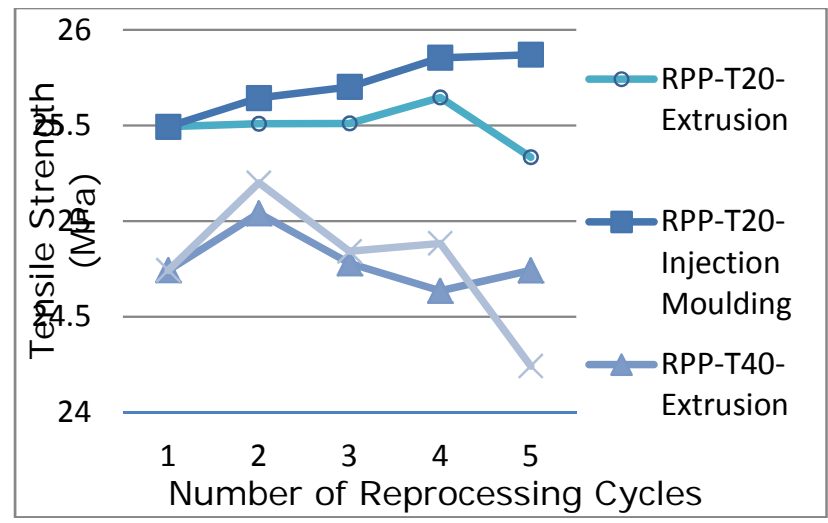

FIGURE XVII. PLOT OF TENSILE STRENGTH (MPA) AGAINST NUMBER OF INJECTION MOULDING CYCLES COMPARING WITH EXTRUSION CYCLES.

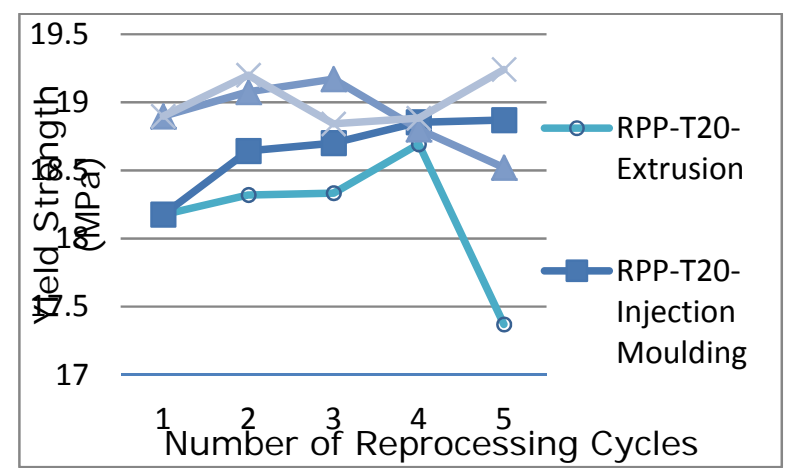

FIGURE XVIII. PLOT OF YIELD STRENGTH (MPA) AGAINST NUMBER OF INJECTION MOULDING CYCLES COMPARING WITH EXTRUSION CYCLES.

As shown in those figures, the materials processed by multiple injection moulding cycles are still preserving some good characteristics as the same as those being processed by multiple extrusion cycles. The tensile strength and yield strength are increased with number of injection moulding cycles, which would imply the increase of crystallinity as mentioned before. All tensile properties of RPP-T40 were increased initially, and then decreased with further re-injection moulding, for it is possible that crystallinity degree of RPP-T40 has reached certain limit, and the amorphous phase increased with further reprocessing.

For the injection moulding cycles involved shredding procedure, which also could be considered as an elevated temperature and high shear rate procedure, the materials endure twice such processes when compared to extrusion set. The chain-scission effect took the ruling place in material matrix, and it would explain the lower tensile modulus than extrusion set.

To sum up, the recycled PP/talc composites still maintain some good performance during reprocesses, and were more stable when comparing to both virgin and recycled PP in most properties, as shown in the figures Table.2. Thus, reusing of rejected parts which made from the talc filled recycled composites could be feasible. 


\section{SUMMARY}

The purpose of this paper is to investigate the effect of reprocessing on recycled material, for fulfilling the knowledge gap resulted from lack of such research and promoting the use of recycled plastic, and using recycled plastics has been already proved to be both economic and environmental-friendly.

For the first time, recycled PP was compounding with talc and coupling agent with different concentration for reprocessability study, where virgin and recycled PP were used as comparatives. The materials were subjected to 5 reprocessing cycles from two different routes, extrusion and injection moulding. The experimental part consists of mechanical, rheological and thermal.

The results showed the talc content has similar effect as it did in virgin PP, such as performance enhancing and stabilization. The recycled $\mathrm{PP} /$ talc composites were superior than virgin PP in most properties, and were more stable under multiple reprocessing cycles than both virgin and recycled PP. In both reprocessing routes, the performances of the recycled $\mathrm{PP} /$ talc composites were similar and constant, it showed the potential of using recycled materials.

There are still something unclear in this moment which displayed in complicated pattern of some properties. It requires further study to understand the competing mechanisms within recycled polymer composites under reprocessing, and how talc stabilize the recycled material.

\section{ACKNOWLEDGEMENTS}

This work was financially supported by the Innovation Team of Ningbo Science and Technology Bureau (2011B81006), International Technological Cooperation Project of the Ministry of Science and Technology (2012DFG91920) and Industrial Technology Innovation and Industrialization Project of Ningbo (2014A35001-2).

\section{REFERENCES}

[1] Directive 2000/53/EC of the European Parliament and of the Council of 18 September 2000 on end-of life vehicles - Commission Statements. Official Journal L 269, 21/10/2000, P.0034-0043.

[2] Directive 2002/96/EC of the European Parliament and of the Council of January 27th 2003 on waste electrical and electronic equipment (WEEE).

[3] [3] Directive 2012/19/EU of the European Parliament and of the Council of 4 July 2012 on waste electrical and electronic equipment (WEEE).

[4] Scaffaro, R., Botta, L., and Di Benedetto, G., Physical properties of virgin-recycled ABS blends: Effect of post-consumer content and of reprocessing cycles, Euro. Poly. 48 (2012) 637-648.

[5] Makuta, M., Moriguchi, Y., Yasuda, Y. and Sueno, S., Evaluation of the effect of automotive bumper recycling by life-cycle inventory analysis. J. Mater. Cycle. Waste. Manag., 2 (2000) 125-137.

[6] Valenza, A. and La Mantia, F.P., Recycling of polymer waste: Part II-Stress degraded polypropylene, Poly. Degrad. Stab., 20 (1988) 63-73.

[7] Ehrig, R.J., Plastics Recycling: Products and Process, Hanser, New York, 1992.

[8] La Mantia, F.P., Recycling of PVC and Mixed Plastic Waste, ChemTec Publisher, Toronto, 1996.

[9] Samperi, F., Puglisi, C., Alicata, R. and Montaudo, G, Thermal degradation of poly(butylene terephthalate) at the processing temperature, Poly. Degrad. Stab., 83 (2004) 11-17.
[10] Rex, I., Graham, B.A. and Thompson, M.R., Studying single-pass degradation of a high-density polyethylene in an injection molding process., Poly. Degrad. Stab., 90 (2005) 136-146.

[11] Zhou, Y., Rangari, V., Mahfuz, H., Jeelani, S., and Mallick, P.K., Experimental study on thermal and mechanical behavior of polypropylene, talc/polypropylene and polypropylene/clay nanocomposites, Mater. Sci. Eng. A., 402 (2005) 109-117.

[12] Scaffaro, R., La Mantia, F.P., and Dintcheva, N.T., Effect of the additive level and of the processing temperature on the re-building of post-consumer pipes from polyethylene blends, Euro. Poly., 43 (2007) 2947-2955.

[13] [13] Guerrica-Echevarría, G., Eguiazábal, J.I., and Nazábal, J., Effects of reprocessing conditions on the properties of unfilled and talc-filled polypropylene, Poly. Degrad. Stab., 53 (1996) 1-8.

[14] González-González, V.A., Neira-Velázquez, G., and Angulo-Sánchez, J.L., Polypropylene chain scissions and molecular weight changes in multiple extrusion, Poly. Degrad. Stab. 60 (1998) 33-42.

[15] Su, K.H., Lin, J.H., and Lin, C.C., Influence of reprocessing on the mechanical properties and structure of polyamide 6, J. Mater. Proc. Technol. 192-193 (2007) 532-538.

[16] Beg, M.D.H., and Pickering, K.L., Reprocessing of wood fibre reinforced polypropylene composites. Part I: Effects on physical and mechanical properties, Compos. A: Appl. Sci. Manuf., 39 (2008) 1091-1100.

[17] Rahimi, M., Esfahanian, M., and Moradi, M., Effect of reprocessing on shrinkage and mechanical properties of ABS and investigating the proper blend of virgin and recycled ABS in injection molding, J. Mater. Proc. Technol., 214 (2014) 2359-2365

[18] Brennan, L.B., Isaac, D.H. and Arnold, J.C., Recycling of acrylonitrile-butadiene-styrene and high-impact polystyrene from waste computer equipment, J. Appl. Poly. Sci., 86 (2002) 572-578.

[19] Díez-Gutiérrez, S., Rodríguez-Pérez, M.A., De Saja, J.A., and Velasco, J.I., Dynamic mechanical analysis of injection-moulded discs of polypropylene and untreated and silane-treated talc-filled polypropylene composites, Poly., 40 (1999) 5345-5353.

[20] Denac, M., Musil, V., Šmit, I., and Ranogajec, F., Effects of talc and gamma irradiation on mechanical properties and morphology of isotactic polypropylene/talc composites, Poly. Degrad. Stab., 82 (2003) 263-270.

[21] Gafur, A., Nasrin, R., Mina, F., Bhuiyan, A.H., Tamba, Y., and Asano, T., Structures and properties of the compression-molded isotactic-polypropylene/talc composites: Effect of cooling and rolling, Poly. Degrad. Stab., 95 (2010) 1818-1825.

[22] Mnif, N., Massardier, V., Kallel, T., and Elleuch, B., New (PP/EPR)/nano-CaCO3 based formulations in the perspective of polymer recycling. Effect of nanoparticles properties and compatibilizers, Poly. Adv. Technol., 21 (2010) 896-903.

[23] Wang, K., Bahlouli, N., Addiego, F., Ahzi, S., Rémond, Y., Ruch, D., and Muller, R., Effect of talc content on the degradation of re-extruded polypropylene/talc composites, Poly. Degrad. Stab., 98 (2013) 1275-1286.

[24] Boumbimba, R.M., Wang, K., Bahlouli, N., Ahzi, S., Rémond, Y., and Addiego, F., Experimental investigation and micromechanical modeling of high strain rate compressive yield stress of a melt mixing polypropylene organoclay nanocomposite, Mech. Mater., 52 (2012) 58-68.

[25] Bourmaud, A., and Baley, C. Investigations on the recycling of hemp and sisal fibre reinforced polypropylene composites, Poly. Degrad. Stab., 92 (2007) 1034-1045.

[26] Bahlouli, N., Pessey, D., Raveyre, C., Guillet, J., Ahzi, S., Dahoun, A., Hiver, J.M., Recycling effects on the rheological and thermomechanical properties of polypropylene-based composites. Mater. Des., 33 (2012) 451-458.

[27] [27] Personal communication with workshop manager of Ningbo Tokai Minth Automotive Parts Co., Ltd. on 21/05/2012.

[28] Lindahla, P., Robèrta, K.H., Nya, H. and Bromana, G., Strategic sustainability considerations in materials management, J. Clean. Prod. 64 (2014) 98-103. 
[29] Plastics - Determination of temperature of deflection under load - Part 2: Plastics and ebonite, published by the International Organization for Standardization (ISO), 2004.

[30] Plastics - Standard atmospheres for conditioning and testing, published by the International Organization for Standardization (ISO), 2008.

[31] Plastics - Determination of tensile properties - Part 2: Test conditions for moulding and extrusion plastics, published by the International Organization for Standardization (ISO), 2012.

[32] Plastics - Determination of flexural properties, published by the International Organization for Standardization (ISO), 2010.

[33] [33] Statistical interpretation of test results - Estimation of the mean -Confidence interval, published by the International Organization for Standardization (ISO), 1980.

[34] Bernardo, C.A., Cunha, A., and Oliveira, M.J., The recycling of thermoplastics. Prediction of the properties of mixtures of virgin and reprocessed polyolefins, Poly. Eng. Sci. 36 (1996) 511-519.

[35] Canevarolo, S.V., Chain scission distribution function for polypropylene degradation during multiple extrusions, Poly. Degrad. Stab., 70 (2000) 71-76.

[36] GU, F., Hall, P., Miles, N.J., Ding, Q., and Wu, T., Improvement of mechanical properties of recycled plastic blends via optimizing processing parameters using the Taguchi method and principal component analysis, Mater. Des., 62 (2014) 189-198

[37] Wang, K., Addiego, F., Bahlouli, N., Ahzi, S., Rémond, Y., and Toniazzo, V., Impact response of recycled polypropylene-based composites under a wide range of temperature: Effect of filler content and recycling, Compos. Sci. Technol., 95 (2014) 89-99. 